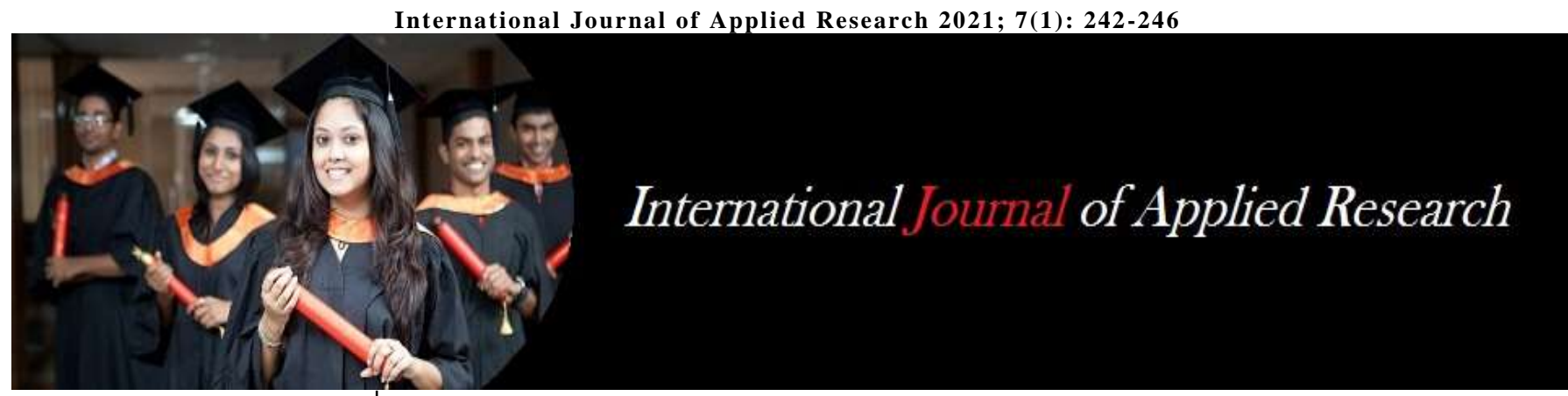

ISSN Print: 2394-7500

ISSN Online: 2394-5869

Impact Factor: 8.4

IJAR 2021; 7(1): 242-246

www.allresearchjournal.com

Received: 27-10-2020

Accepted: 08-12-2020

Akshay Joshi

S.S.V.P.S B.S. Deore

College of Engineering, Dhule,

Maharashtra, India

Dr. ER Deore

S.S.V.P.S B.S. Deore

College of Engineering, Dhule,

Maharashtra, India

\section{Design, development and performance analysis of perforated muffler in the automobile exhaust system}

\author{
Akshay Joshi and Dr. ER Deore \\ DOI: https://doi.org/10.22271/allresearch.2021.v7.i1d.8185
}

\begin{abstract}
A muffler (or a silencer) is one of the important parts of an engine system used in an exhaust system to reduce the exhaust gas noise level. Although its' primary role is to reduce the exhaust gas noise level, but it can also play a role in the car's overall performance. An engine is able to generate more power faster, if it is able to get rid of all of the exhaust gases. By their nature, mufflers restrict the exhaust gases or create back pressure which has a negative effect on engine efficiency. The literature review reveals that it depends upon various factors such as muffler geometry, number of perforations and its' diameter; etc. The objective of this study is to achieve a good fuel economy. The performance of the muffler is assessed by analyzing average fuel consumption, average mechanical efficiency and firing. The tests are run over the muffler before and after its' modifications with the help of a diesel engine. The results obtained from first testing are graphically plotted and are compared with the results from second testing, containing the required modifications, which too are graphically plotted. After the comparison, it is found that the modified muffler has achieved good fuel economy with increased overall average with smooth firing, also the problem of black soot is reduced which overall increased its' lifespan.
\end{abstract}

Keywords: Back pressure, good fuel economy, average fuel consumption, average mechanical efficiency, black soot

\section{Introduction}

Internal combustion engine is a major source of noise pollution. These engines are used for various purposes such as, in power plants, automobiles, locomotives and in various manufacturing machineries. The main sources of noise in an engine are the exhaust noise as well as the noise produced due to friction in various parts of the engine in which exhaust noise is dominant. To reduce this noise, various kind of automotive mufflers are designed due to which muffler design has become an important research area for the automotive companies under the new regulations and standards for noise emission. The performance of any muffler is examined by certain parameters which are transmission loss and back pressure. The transmission loss gives a value in decibel $(\mathrm{dB})$ that corresponds to the ability of the muffler to dampen the noise while the engine exhaust back pressure which has a direct impact on percentage fuel consumption.

Apart from transmission loss, mufflers generally results in the maximum back pressure which have always been faced by designers of exhaust systems. The increased interest in exhaust pressure has been caused by fitting diesel engines with diesel particulate filters (DPF), and the introduction of complex after treatment systems in general. Installation of DPF's often raises concerns about increased back pressure. At increased back pressure levels, the engine has to compress the exhaust gases to a higher pressure which involves additional mechanical work by the exhaust turbine which can affect intake manifold boost pressure. This can lead to an increase in fuel consumption, $\mathrm{CO}$ emissions and exhaust temperature. Other effects on diesel combustion are possible which depends on the type of engine. The increased back pressure may affect the performance of the engine. In exhaust systems with a DPF, the back pressure can rise to significantly higher levels-especially if the filter is heavily loaded with soot. All engines have a maximum allowable engine back pressure specified by the engine manufacturer. Operating the engine at excessive back pressure might invalidate the engine warranty. To facilitate retrofitting of existing engines with DPFs, especially using passive filter systems,
Corresponding Author: Akshay Joshi S.S.V.P.S B.S. Deore College of Engineering, Dhule, Maharashtra, India 
emission control manufacturers and engine users have been requesting that engine manufacturers increase the maximum allowed back pressure limits on their engines.

The objective of this project is to investigate the various factors that have a direct relation with back pressure created in the exhaust system. The testing was conducted on a CI engine, before and after the modifications done in the muffler. This paper shall experimentally explain the optimization of the exhaust muffler to increase the fuel efficiency of the vehicle. From the data measured and tabulated, the applied modifications have successfully dropped the fuel consumption and exhaust temperature.

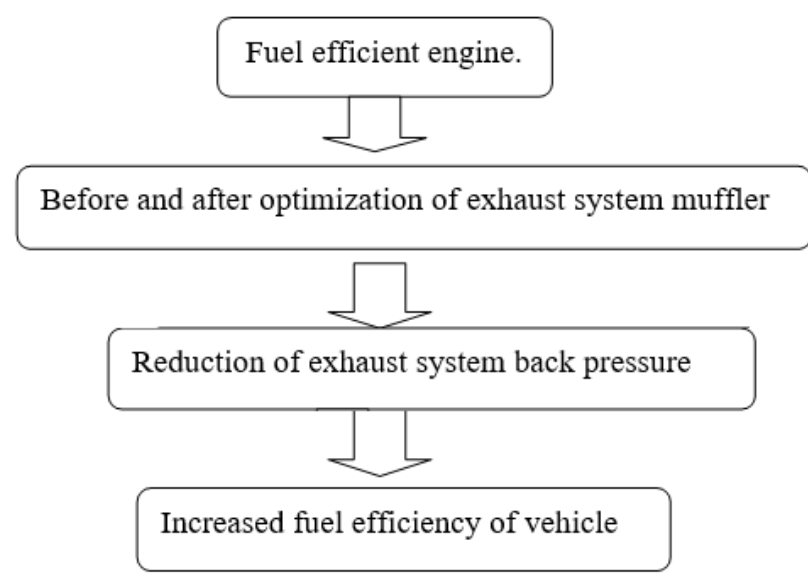

\subsection{General design of perforated muffler 1.1.1 Problem Statement}

To fabricate a muffler for increased fuel efficiency needs testing of a muffler before and after modification by using a diesel engine. The muffler is tested on a diesel engine before and after modifications with five trails each, overall iterations averaged out to plot graphs for comparison.

\section{Experimental conditions and Setup}

2.2.1 Engine specifications - Single cylinder, 4-stroke, and water-cooled diesel engine electrical dynamometer.

1. Rated power $=3.67 \mathrm{Kw}$

2. Rated speed $=1500$ r.p.m

3. C.V. of fuel $=4390 \mathrm{~kJ} / \mathrm{kg}$

4. Density of fuel $=835 \mathrm{~kg} / \mathrm{m}^{3}$

5. Room temperature $=30^{\circ} \mathrm{C}$

6. Atmospheric pressure $=1.01325 \mathrm{bar}$

7. Generator: Single phase A.C., Efficiency $=80 \%$

Above are the conditions in which the muffler was tested before and after modifications.

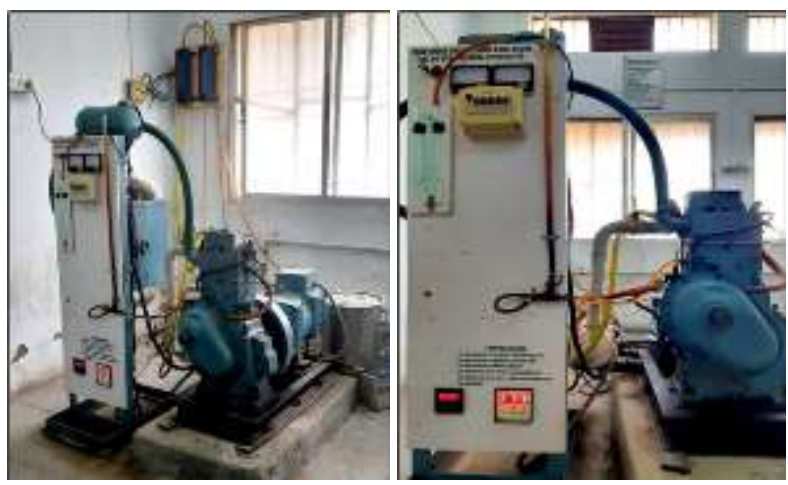

Fig 1: Diesel Engine - Experimental apparatus for testing the muffler
2.2.2 Setup; Initially, the muffler is connected to engine with constant load and is started by cranking. The knob of fuel measuring burette on the fuel supply is opened and the time is measured for $10 \mathrm{ml}$ drop of fuel in seconds. All corresponding temperatures are recorded by temperature scanner. The speed is recorded with the help of r.p.m indicator. The same is repeated for five trials and is recorded accordingly. After measuring the voltage and current; brake power, indicated power, fuel consumption, brake specific fuel consumption and mechanical efficiency are calculated.

\subsubsection{Following various graphs from the above results are plotted \\ 1. Fuel consumption Vs Brake power - Test 1 \\ 2. Fuel consumption Vs Brake power - Test 2 \\ 3. Comparison of Brake power Vs Mechanical efficiency \\ 4. Comparison of Test 1 results Vs Test 2 results}

\subsection{Experimental testing 1 and Finalization:}

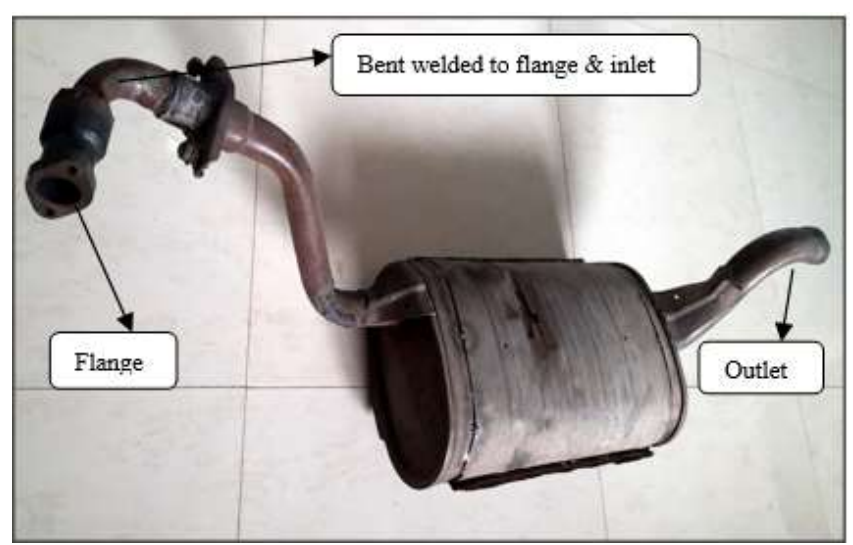

Fig 2: General muffler

The general muffler that has been taken for experimentation (as shown in Fig 2) is put to testing. The inlet of muffler is welded to a flange and a bent for an easy fitting with the diesel engine. After arriving at the satisfactory arrangement of the muffler with the engine and the rigid support, the value is now input for the several iterations to get the readings for unmodified muffler. The first testing will be for five trails with constant load. Finally, the results are tabulated, averaged out, calculated and then plotted graphically.
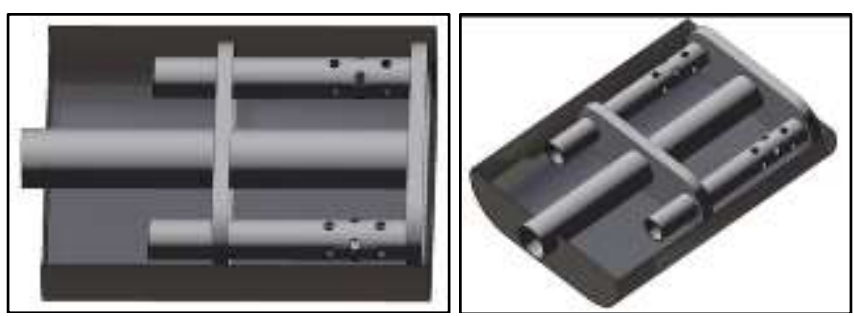

Fig 3: Sectional CAD model of the muffler with circular holes

CAD model of the muffler (as shown in Fig 3) is created by using CATIA V5 software. Total length of geometry of muffler is $400 \mathrm{~mm}$. It has baffle 1 and baffle 2 with holes on it, also pipes has circular perforations on it.

\subsubsection{Specifications used for the model are}

Minor Diameter: 100mm

Major Diameter: $180 \mathrm{~mm}$ 
Total Length: $400 \mathrm{~mm}$

The muffler model is constructed using these parameters in CATIA V5. Fig 3 shows two different views of geometries used for the construction of the model. In Fig 3 the perforated holes are circular i.e. less exhaust area.

\subsection{Graph plotted for Fuel consumption Vs Brake power - Test 1}

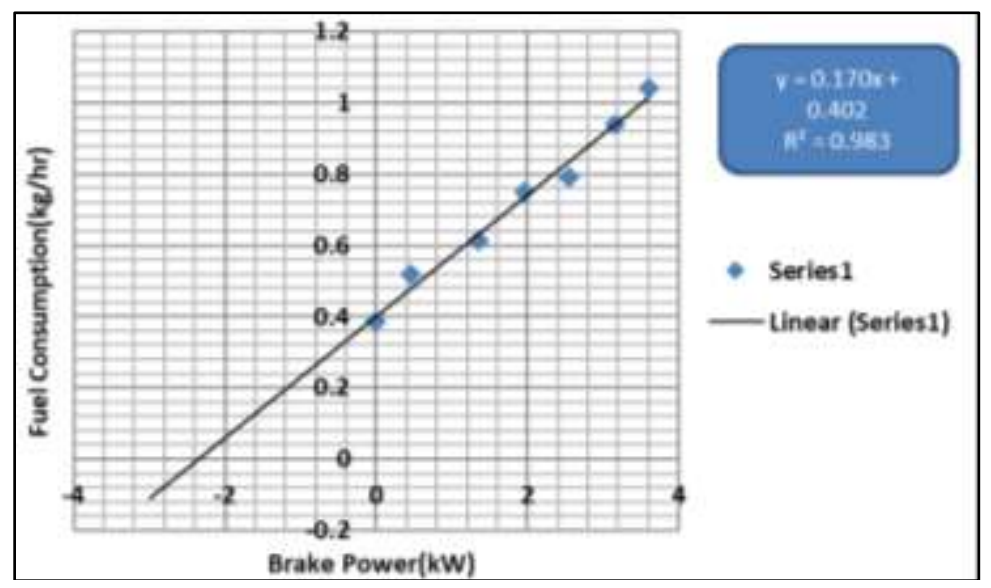

Fig 4: Fuel consumption Vs Brake power graph

\section{Modified design of perforated muffler - Test 2 3.1 Modifications to the muffler}

After accumulating satisfactory results from Test 1 , the general muffler is modified for the Test2. Applying the simple modification, the circular perforated holes are converted into elliptical shape (as shown in Fig 5). This modification leads to increase in exhaust area which qualitatively reduces the back pressure. It correspondingly reduces the percentage fuel consumption, which is confirmed by the results of Testing2 conducted on the modified muffler with the help of specified diesel engine.

\subsection{Experimental conditions and Setup:}

3.2.1 Engine specifications and setup - For the Test 2, the engine specifications are kept same as that of the Test 1 with similar experimental setup. The muffler is connected to engine with constant load and started by cranking. Similarly the time is measured for $10 \mathrm{ml}$ drop of fuel in seconds and all the corresponding temperatures are recorded by temperature scanner while the speed is recorded with the help of r.p.m indicator measuring the same repetition for constant load. Similar to Test 1; brake power, indicated power, fuel consumption, brake specific fuel consumption and mechanical efficiency are calculated. After proper calculations of the required values, graphs are plotted.

\subsection{Experimental testing 2 and Finalization}

The general muffler that has been taken for Test 1 (as shown in Fig2) is modified as above and put to testing. Similar to Test 1 , the muffler is satisfactorily fitted to the diesel engine and the rigid support. Now the value is input for the several iterations to get the readings for modified muffler. The second testing too will be for five trails with constant load. Finally, the results are tabulated, averaged out, calculated and then plotted graphically.

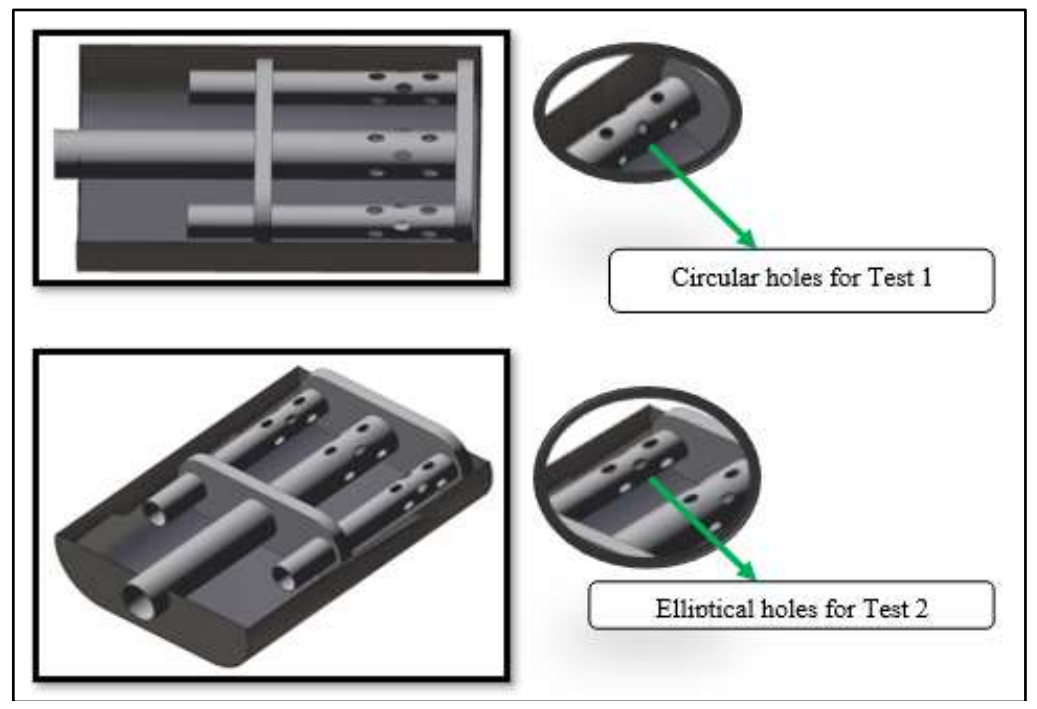

Fig 5: Sectional CAD model of modified muffler

CAD model of the modified muffler (as shown in Fig 6) is created by using CATIA V5 software. Total length of geometry of muffler is $400 \mathrm{~mm}$. It has baffle 1 and baffle 2 with holes on it, also pipes has now elliptical perforations on it. 


\subsubsection{Specifications used for the modified model are:}

Minor Diameter: $100 \mathrm{~mm}$

Major Diameter: $190 \mathrm{~mm}$

Total Length: $400 \mathrm{~mm}$
The modified muffler model is constructed using these parameters in CATIA V5. Fig 6 shows two different views of geometries used for the construction of the model. In Fig 6 the perforated holes are elliptical i.e. more exhaust area.

\subsection{Graph plotted for Fuel consumption Vs Brake power - Test 2}

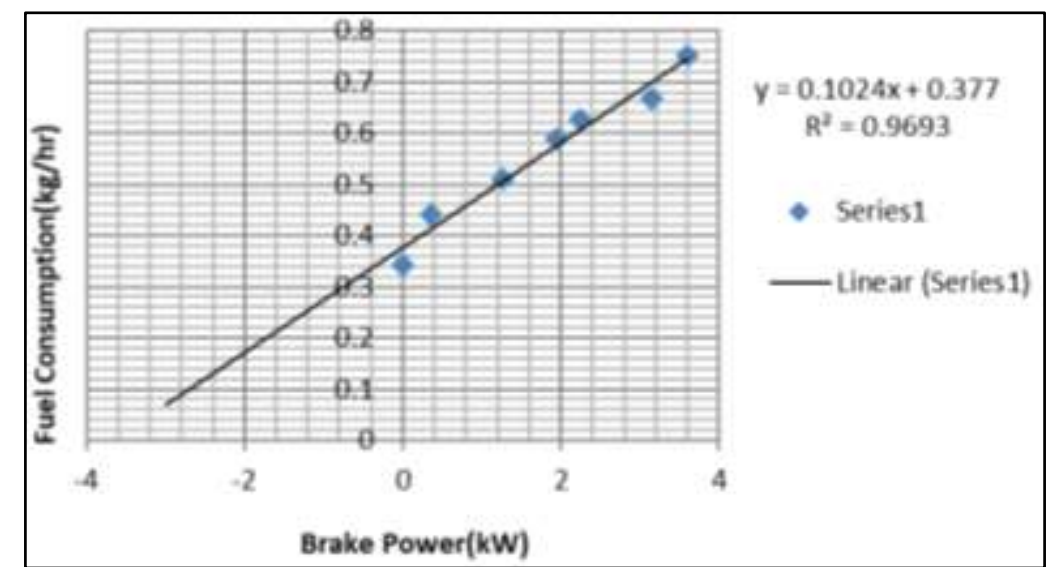

Fig 6: Fuel consumption Vs Brake power graph

\subsection{Comparison of before and after modifications}

Comparisons of two geometries are shown in shown in Fig 7 and Fig 8. For the comparison, blue color is used for Test 1 and red color is used for Test 2. It shows that Test 2 successfully gives more percentage fuel efficiency than Test 1 , so geometrical aspect of modified muffler is preferable.

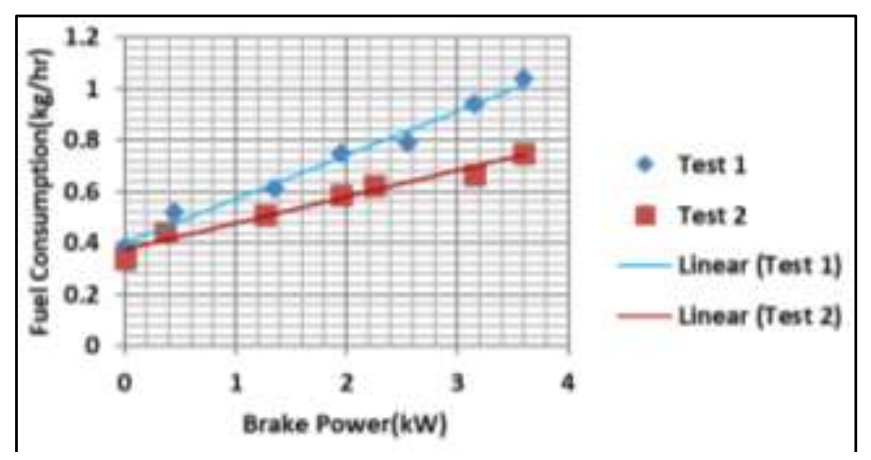

Fig 7: Fuel consumption Vs Brake Power Graph

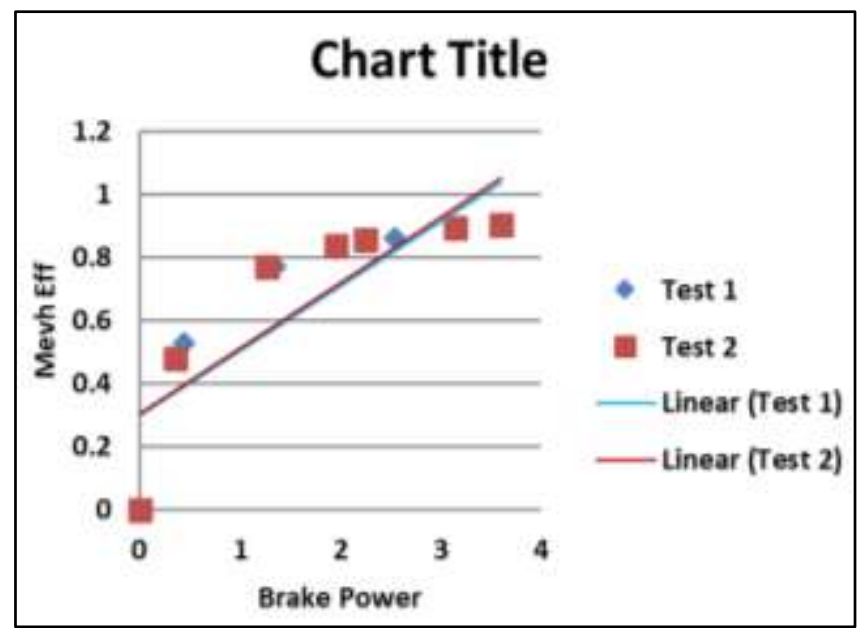

Fig 8: Mechanical Efficiency Vs Brake Power Graph

\section{Conclusion}

The purpose of this experiment was to conduct design and development of the general muffler in order to determine percentage fuel consumption and to gain a good fuel economy and suggest changes in the general muffler. In this study, the general muffler is experimented to obtain the required results. The testing was done before and after modifications, experimentally and was compared accordingly. The graphs obtained from this experimental study have shown a good agreement with the required results.

This experimental study has led to conclusions that the modified muffler with increased exhaust area achieved good fuel economy with overall increase in efficiency. The modifications have also reduced the soot formation, which has decreased the choke up problems of the muffler and have increased muffler's lifespan.

\section{Acknowledgement}

Special thanks to Dr. E.R. Deore, (Prof. in Mechanical Engineering Department, SSVPS College of Engineering, Dhule) for his valuable contribution in developing the IJMRD article template.

\section{References}

1. Vijay Mundhe M, Dr. Deore ER. Design and Optimization of Perforated Muffler in an Automobile Exhaust System, International Journal of Applied Research, ISSN: 2314-5869, 2015;1(8):390-395.

2. Dr. Mylaudy, Rajadurai S, Naveen S. Muffler Optimization for Increased Fuel Efficiency Iterations Using Taguchi Orthogonal Array for Controlling $\mathrm{CO}_{2}$, International Journal of Innovative Science, Engineering and Technology 2015;2(3). 2015, 289-295.

3. Rajasekhar Reddy M, Madhava Reddy K. Design and Optimization of Exhaust Muffler in Automobiles, International Journal of Automobile Engineering Research and Development (IJAuERD), ISSN 22774785, 2012;2(2):11-21.

4. Christopher George T, Prof. Vinod Raj HG. Energy Efficient Design and Modification of an Automotive Exhaust Muffler for Optimum Noise, Transmission Loss, Insertion Loss and Back Pressure: A Review, IOP Conf. Series: Materials Science and Engineering 

2018;377:012127.
Doi:
$10.1088 / 1757-$

899X/377/1/012127

5. Yunshi Yao, Shaodong Wei, Jinpeng Zhao, Shibin

Chen, Zhongxu Feng Jinxi Yue. Experiment and CFD Analysis of Reactive Muffler Research Journal of Applied Sciences, Engineering and Technology 2013, 3282-3288.

6. Potente, Daniel. General Design Principles for an Automotive Muffler in Proceedings of Acoustics, November 2005, 9-11.

7. Suganeswaran K, Dr. Parameshwaran R, Amirthamani S, Palanimohan D. Design and Optimization of Muffler for Manufacturing. International Journal of Innovative Research in Science Engineering and Technology 2014;3(4). 